\title{
Common Sports Injuries amongst the Elite Women Basketball Players of India
}

\author{
Raspreet Sidhu ${ }^{1}$ Anjali Chhikara ${ }^{2}$, Dr. D.P. Sharma ${ }^{3}$ \\ ${ }^{I}$ (Assistant Professor, Physical Education, Mata Sundri College for Women, University of Delhi,India) \\ ${ }^{2}$ (Physical Education Teacher, Queen Mary's School, Delhi,India) \\ ${ }^{3}$ (Associate Professor, I.G.I.P.E.S.S., Vikas Puri, University of Delhi)
}

\begin{abstract}
An injury is a common phenomenon in the field of sports. Ranging from amateurs to the most seasoned sports personalities, almost every one faces the brunt of an injury at some point in their sporting careers. To gauge the effect and extent of these injuries, the members of the Indian women basketball team were examined for common sports injuries. While they represent the country at various international tournaments round the year, the results of the survey painted a very dismal picture.

The longevity of a sports person's career depends critically on the severity of an injury. In some cases, severe injuries have an intense impact immediately. While on the other hand, there are also instances when an injury is ignored and remains untreated; this becomes worse and hinders the crucial functioning of a sports person on the field. Irrespective of the case, it is essential that all such injuries be avoided at all levels of the sport for its growth and development.

It is an endeavor by the research scholars to isolate the most common and frequently occurring injuries so that the players, coaches, doctors and physiotherapists can concentrate and work on the preventive measures for them.
\end{abstract}

Key Words: Basketball, Prevention, Sports Injuries, Women

\section{Introduction}

Basketball has gained more attention these last 10 years in the scientific literature of injury surveillance. Basketball appears to have the highest frequency of injuries among limited contact sports. It is even referred to as being more dangerous, with a higher injury risk, than contact sports. Consequently, the intensity and aggressiveness of the game should not be underestimated, because the contemporary game of basketball puts full emphasis on the speed and power of competitors. Strength and quickness are necessary to control an opponent's position, "muscle" a rebound, or "power" a shot, all of these are prerequisites for a successful basketball career.

Even though injuries in all sports are increasing ( in spite of technological advances in safety equipment, appropriate emphasis on proper physical conditioning and attention to the rules ) the variables that serve to protect or pre-dispose sports participation to injury in a given sport remain to be better defined. The axiological determinants are both complex and multiple and include: type of sports experience, equipment used, level of competitive involvement, coaching technique and physical playing conditions. These components interact with the individuals physical characteristics.

In recent years, increasing members of people of all ages have been heeding their health professionals advice to get active for all the health benefits exercise has to offer. But for some people, particularly those who overdo or who don't properly train or warm up, these benefits can come at a price: sports injury. Fortunately, most sports injuries can be treated effectively, and most people who suffer injuries can return to satisfying level of physical activity after an injury. Sports injuries can be prevented if people take proper precautions.

\subsection{Selection Of The Subjects}

\section{Procedure And Methodology}

The survey was based upon the injuries of women Basketball players participating at the international level. The subjects were the players selected for the India camp for the year 2012-2013.

\subsection{Administration Of The Test}

For the fulfillment of the study, the data was collected by filling the checklist prepared with the help of a guide and other experts of the field. The response taken was on a two point scale i.e. occurrence and non occurrence of the injury. 


\subsection{Collection Of Data}

The necessary data was collected by filling of checklist from the selected International women Basketball players.

\subsection{Statistical Techniques}

The responses elicited in the checklist were analyzed by adopting percentage method, which further was exhibited in the form of a graph.

\section{Result}

We observed that the highest weightage was obtained by sprain of flexor/extensor tendons (jammed finger) of the finger, which has a percentile value of 91.67, which makes this location most vulnerable to get injured amongst women basketball players.

Shin bone pain and ankle sprain (inversion) with percentile value of 87.50 percent each can be denoted as the second most common injuries. Lower back pain is also highly common with the percentile value of 83.33 percent.

Other injuries which were seen to be occurring frequently to women basketball players include sprain of ligaments around wrists, which was 75.00 percent and injury on nose, with 66.66 percent among all the injuries. Rotator cuff tears and quadriceps strain accounted for 62.50 percent each among all the injuries.

Out of the total number of injuries occurred to all the players, black eye and sprain of collateral ligaments of fingers had a percentile value of 58.33 percent each whereas concussion, with 54.17 percent . There are few injuries which do not occur very frequently in women basketball players and those are hamstring strain, sprain of meniscus or lateral meniscus and strain of flexion/extension/abduction/adduction muscles of the hip with 50.00, 50.00 and 41.67 percent respectively among all the injuries.

Cut over the eyebrow and blisters with 33.33 percent each are amongst the injuries which occurred to very few basketballers. Other injuries suffered by the similar strength of players includes calf muscle strain, whiplash injury, sprain of ACL/PCL and dislocation of radio-ulnar joint with a percentile value of 29.17, 25.00, 25.00 and 20.83 respectively among all the injuries occurred.

There are few injuries which occurred rarely to women basketball players. Those injuries include ankle sprain (eversion) and jammed toe with 16.67 percent each amongst all the injuries. Contusion, strain of cervical spine, fracture of wrist bones and stress fracture of ankle are also amongst rarest injuries reported by women basketball players contributing 12.50 percent each amongst all the injuries.

The lowest weightage is obtained by dislocated jaw and dislocation of ankle, both with 8.33 percent among all the injuries. Slipped disc, fracture of ankle, dislocation of hip joint and dislocation of elbow with a percentile value of 4.17 each are the minimum occurred injuries amongst the total injuries suffered by women basketball players.

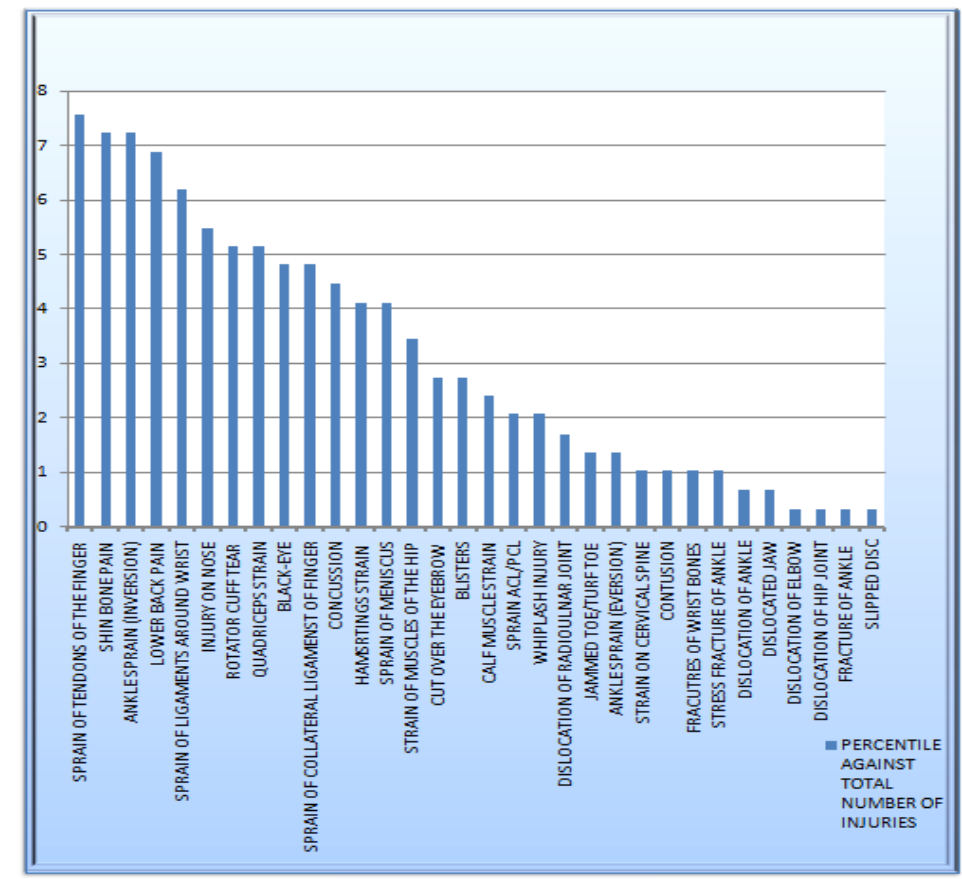

Figure 1. Percentile against total number of injuries 


\section{Discussion}

In basketball as ball handling is inevitable and where passing, receiving, shooting and rebounding are most important. At the international level, the ball is made of leather coating with an air pressure of 7 to $9 \mathrm{lbs}$ due to which the frequency of finger injuries taking place are high. As a result the percentile of finger injuries is the highest amongst all the injuries. Author feels in this fast running world, there should be some protective measures inducted from respective field to minimize these injuries. The author has strong opinion that this may lead to enhancement in the standard of the game.

Fingers sprain injury is immediately followed by shin bone pain, lower back pain and ankle sprain of inversion movement. These are also majorly occurring injuries. Basketball is the second fastest game in the world. It involves rigorous movements of upper and lower body leaving the athlete vulnerable to various injuries. The twisting, turning, jumping and landing movements leads to strain of lower leg and lower back immensely.

There are some injuries which can be called above average. These includes wrist sprain, nose injury, rotator cuff tear, quadriceps strain, black-eye, sprain of collateral ligament of finger, concussion, hamstring strain and sprain of meniscus. Researcher feels that these injuries are common in contact of limited contact sports in which basketball is also included. Other than the nature, the intensity of the game and vigorous training given to prepare basketball players are the causes making them prone to above mentioned common injuries. Though, the rate of occurring of these injuries was not as high as in respect to above mentioned injuries, still these injuries need to be given attention for consideration of adopting protective measures.

Dislocation of elbow, dislocation of hip joint, fracture of ankle, slipped disc, dislocated jaw, dislocation of ankle, stress fracture of ankle, fractures of wrist bones and contusion has minimum occurrence. It is rare because comparatively these joints are stronger than finger joints and all these parts do not come in direct contact with the ball.

\section{Conclusion}

I wish to quote the following statements, "Injuries are the ornaments of sports" and also that "Prevention is better than the cure". One cannot avoid the injuries but the success lies in minimizing these injuries. As Troy Vincent said, "Injuries are part of the game, but sometimes we can avoid them by just practicing our techniques". It is an endeavour by the researchers to highlight the most common occurring injuries to women basketball players so that proper preventive measures can be undertaken in advance to minimize the occurrence these injuries. It will definitely help the players to give a persistent and prolonged performance which will ultimately result in the development of the sport.

\section{Books}

[1] Bird R. Stephen., et. al.,"Sports Injuries: Causes, Diagnosis, Treatment and Prevention" (1997)

[2] Hampings. R, "Precautions to be taken to avoid injuries" (2005)

[3] Shamus Cric and Shamus Jeniffer "Sports Injury Prevention and Rehabilitation" (2008)

[4] Hutton, "An Introductionto Medical Terminology for Health Care" (June 2006)

[5] Dorland, "Dorland's Illustrated Medical Dictionary" (2011)

[6] Malachitsg .R, "Essentials of Sports Medicine" (2004)

[7] Weldons .M \& Hill .R.H, "The efficacy of stretching for prevention of exercise related injury" (2003)

[8] Thacker Stephen B., "Medicine and Science in Sports and Exercise" (2011)

[9] Thacker .S.B, "Prevention of knee injuries in sports" (2010)

\section{Journals And Dissertations}

[10] Cumpselke et al "Prospective Epidemiological Study of Basketball injuries during competitive season: Ankle sprains and overuse knee injuries", Journal of sports science and medicine; 2007, pp- 204-211; http://www.jssm.org

[11] Mckay .G.D. et al., "British journal of sports medicine";2001, pp- 103-108; http://bjsm.bmj.com/content/35/2/103.full

[12] Arendt Elizabeth "Knee injuries pattern among men and women in collegiate basketball and soccer NCAA data", The American Journal of Sports Medicine; Vol.23, 1995, pp 694-701

[13] Beynnon Bruce .D "Predictive factors for lateral ankle sprains", Journal of Athletic Training; 2002, pp 376-380

[14] Dvorak Jiri \&Junge Astrid, "Football injuries and physical symptoms", American Journal Sports Medicine; Vol.28; no. supp 5 S3 to S9, 2002

[15] D.F. Murphy, "Prospective studies on risk factors for lower extremities injury", British Journal Sports Medicine; 2003, pp 13-29

[16] Peter M. Boruta, "Acute lateral ankle ligament injury", Foot and ankle International; volume 11, 1990, pp 107-113 